\title{
Proposta de um modelo de avaliação de desempenho para apoiar decisões de investimento em empresas da Bovespa: A perspectiva da MCDA-C
}

Sandro César Bortoluzzi
Doutorado em Engenharia de Produção pela Universidade Federal de Santa Catarina -
UFSC
Professor Auxiliar na Universidade Tecnológica Federal do Paraná - UTFPR
Avenida Sete de Setembro, 3165. Rebouças, Curitiba/PR. CEP: $80230-901$

E-mail:sandro@utfpr.edu.br

Sandra Rolim Ensslin Doutorado em Engenharia de Produção pela Universidade Federal de Santa Catarina UFSC

Professor Adjunto na Universidade Federal de Santa Catarina - UFSC Campus Universitário Reitor João David Ferreira Lima. Trindade, Florianópolis/SC.

CEP: $88040-970$

E-mail: sensslin@gmail.com

Leonardo Ensslin

Pós-doutorado - Lancaster University

Professor Titular na Universidade Federal de Santa Catarina - UFSC Campus Universitário Reitor João David Ferreira Lima. Trindade. Florianópolis/SC.

CEP: 88040-970

E-mail: leonardoensslin@gmail.com

Maurício Vasconcellos Leão Lyrio

Doutorando em Administração pela Universidade Federal de Santa Catarina - UFSC Consultor de Planejamento na Secretaria de Estado da Administração - CPLAN Rodovia SC 401, km 5, 4.600. Saco Grande II. Florianópolis/SC. CEP: 88032-000

E-mail: mauriciovll@gmail.com

\section{RESUMO}

O presente artigo objetiva desenvolver um modelo de avaliação de desempenho econômico-financeiro com o fim de apoiar decisões de investimento em empresas participantes da BOVESPA. Este estudo exploratório é guiado pela seguinte questão de pesquisa: Como integrar as percepções de um decisor em um modelo de avaliação de desempenho com vistas a apoiar a seleção de empresas a investir? Apresenta-se a contribuição da Metodologia Multicritério de Apoio à Decisão - Construtivista (MCDA-C), no sentido de levar em consideração a percepção do investidor na construção do modelo de avaliação e integrar os diversos indicadores para que se possa fazer uma avaliação global de desempenho. O modelo foi aplicado em uma sociedade anônima - 
Proposta de um modelo de avaliação de desempenho para apoiar decisões de investimento em empresas da Bovespa: A perspectiva da MCDA-C. Sandro César Bortoluzzi, Sandra Rolim Ensslin, Leonardo Ensslin, Maurício Vasconcellos Leão

Positivo Informática S.A., gerando como resultado global um desempenho de 7 pontos em 2006 e 20 pontos em 2007, o que foi considerado um desempenho pouco competitivo, haja vista que um bom desempenho equivale a 100 pontos. Conclui-se que a Metodologia Multicritério de Apoio à Decisão - Construtivista (MCDA-C) pode auxiliar na avaliação de desempenho econômico-financeiro por meio da integração dos indicadores e fornecer informações úteis para que o investidor possa tomar a decisão que melhor represente suas percepções.

Palavras-chave: Avaliação de Desempenho. Índices Contábeis. Decisões de Investimentos. Metodologia Multicritério de Apoio à Decisão - Construtivista (MCDA-C).

\section{Proposal of a performance evaluation model to support investiment decisions at Bovespa companies: MCDA-C perspective}

\section{ABSTRACT}

The present article aims at developing an economical and financial performance evaluation model with in order of supporting investiment decisions companies participating at BOVESPA. This exploratory study is guided by the following research question: How integrate the perceptions of a decision maker in a model of performance evaluation in order to support the selection of companies to invest? It is intended to present the contribution of Multicriteria Decision Aid - Constructivist (MCDA-C), to consider investor perception in the construction of the evaluation model and integrate the various indicators so that we can make an overall performance assessment. The model was applied to a business corporation - Positivo Informatica SA, generating as an overall result a performance of 7 points in 2006, and 20 points in 2007, which was considered a non-competitive performance, considering that a good performance is equivalent to 100 points. We conclude that the Multicriteria Decision Aid, Constructivist (MCDA-C) can assist in evaluating the financial performance through the integration of the indicators and provide useful information for an investor to make the decision that best represents their perceptions.

Keywords: Performance Evaluation. Indexes Statements. Investment Decisions. Multicriteria Decision Aid - Constructivist (MCDA-C).

\section{INTRODUÇÃO}

Habitualmente, um investidor, quando no momento de decisão de investimento, tem acesso, basicamente, a dois tipos de informações sobre uma empresa constituída na forma de sociedade anônima que deseja investir: (i) informações de mercado 
Proposta de um modelo de avaliação de desempenho para apoiar decisões de investimento em empresas da Bovespa: A perspectiva da MCDA-C.

Sandro César Bortoluzzi, Sandra Rolim Ensslin, Leonardo Ensslin, Maurício Vasconcellos Leão

relacionadas ao preço da ação; e (ii) um conjunto de informações publicadas por essas empresas nos jornais de grande circulação e/ou divulgadas por meio do site da empresa ou da Bolsa de Valores.

As informações divulgadas por essas empresas são: o relatório de administração; as demonstrações contábeis; as notas explicativas; e o parecer dos auditores independentes (IUDíCIBUS et al., 2007), sendo que este trabalho abordará o relatório de administração e as demonstrações contábeis. Em relação às demonstrações contábeis, o trabalho explorará o Balanço Patrimonial (BP) e a Demonstração de Resultado do Exercício (DRE).

Com o relacionamento das contas desses demonstrativos surgem os índices contábeis, que têm como objetivo explicar o desempenho econômico-financeiro das organizações. Segundo Camargos e Barbosa (2005), essa técnica considera os diversos demonstrativos contábeis como fonte de dados, que são compilados em índices, cuja análise histórica possibilita identificar a evolução do desempenho econômico e financeiro.

Os índices contábeis considerados tradicionais pela literatura são divididos em três grupos principais: Índices de Liquidez; Índices de Rentabilidade; Índices de Estrutura de Capital. Conforme Matarazzo (1997), os Índices de Liquidez e os Índices de Estrutura de Capital procuram evidenciar aspectos da situação financeira, e os Índices de Rentabilidade procuram evidenciar aspectos da situação econômica.

A discussão que se faz no meio acadêmico é que esses indicadores contábeis considerados tradicionais são monocritérios, ou seja, são índices que trazem informações importantes, mas, se analisados separadamente, não conseguem demonstrar adequadamente o desempenho econômico-financeiro global da empresa em estudo. Segundo Lima (2003, p.106), "a ciência contábil tradicional utiliza-se, em geral, de métodos de avaliação com um único indicador, uma medida quantitativa de eficiência econômica".

Para suprir essa deficiência, surgiram os métodos multicritérios, que procuram integrar os diversos indicadores de desempenho, proporcionando uma visão global de 
Proposta de um modelo de avaliação de desempenho para apoiar decisões de investimento em empresas da Bovespa: A perspectiva da MCDA-C. Sandro César Bortoluzzi, Sandra Rolim Ensslin, Leonardo Ensslin, Maurício Vasconcellos Leão

desempenho, dessa forma apoiando o processo de tomada de decisão. Segundo Wernke e Bornia (2001), os vários aspectos considerados concomitantemente no processo decisório, principalmente quando envolvem questões estratégicas, tendem a resultar em ações mais bem elaboradas, tanto para quem decide, quanto para quem sofre as consequências das decisões.

Considerando o exposto, este trabalho tem como tema a avaliação de desempenho econômico-financeiro sob uma visão multicriterial, no sentido de desenvolver uma proposta que considere os indicadores contábeis tradicionais e permita, além de uma avaliação pontual do desempenho, uma integração dos diversos indicadores possibilitando uma avaliação global do desempenho da organização. Dessa forma, emerge o problema de pesquisa: Como integrar as percepções de um decisor em um modelo de avaliação de desempenho com vistas a apoiar a seleção de empresas a investir?

O objetivo principal é construir um modelo de avaliação que possibilite a integração dos indicadores contábeis, considerados tradicionais na literatura, utilizando como ferramenta de intervenção a Metodologia Multicritério de Apoio à Decisão Construtivista (MCDA-C), comparando os resultados da avaliação com os relatórios de administração das empresas a fim de identificar o alinhamento destes com os resultados obtidos na avaliação.

Cumpre esclarecer a afiliação teórica do trabalho, no que tange o conceito de avaliação de desempenho: os autores afiliam-se a definição de AD formulada por Igarashi et al. (2008, p.119). Segundo a ótica desses pesquisadores, uma avaliação válida e legítima deve investigar: 
Proposta de um modelo de avaliação de desempenho para apoiar decisões de investimento em empresas da Bovespa: A perspectiva da MCDA-C. Sandro César Bortoluzzi, Sandra Rolim Ensslin, Leonardo Ensslin, Maurício Vasconcellos Leão

(i) o que vai ser avaliado - ou seja, conhecer o objeto da avaliação, incluindo aqui a sua identidade, a cultura sobre a qual esta identidade é construída, as instâncias que respondem pelo objeto a ser avaliado, resultando nos objetivos a serem perseguidos; (ii) como proceder à avaliação - ou seja, identificar como cada objetivo será avaliado e quanto cada objetivo contribui para a avaliação do todo, possibilitando a identificação do perfil de desempenho do objeto avaliado; (iii) como conduzir ao gerenciamento interno - com base na análise das fragilidades e potencialidades identificadas para sugerir ações de aperfeiçoamento - promovendo a alavancagem do desempenho institucional.

Para atingir o objetivo formulado, esse artigo é organizado da seguinte forma: além desta (i) parte introdutória, o (ii) referencial teórico discute os conceitos e a relevância dos indicadores contábeis tradicionais e a emergência dos métodos multicritérios; a seção (iii) metodologia da pesquisa, apresenta o enquadramento metodológico e o instrumento de intervenção utilizado no trabalho; a seguir, a seção (iv) apresenta a proposta de integração dos indicadores contábeis tradicionais por meio da metodologia MCDA-C; a seção (v) operacionaliza o modelo construído: o estudo de caso da empresa Positivo Informática S.A.; finalmente, a última seção (vi) tece considerações finais.

\section{REFERENCIAL TEÓRICO}

Os demonstrativos contábeis e o relatório de administração são fontes de informações para quem pretende investir em empresas constituídas sob a forma de sociedade anônima, mas o simples acesso à essas informações parecem não ser o suficiente para todos os investidores no momento de fazer investimentos. A transformação de informações contábeis em índices contribui para um melhor entendimento da situação econômico-financeira, mas não o suficiente para uma visão integrada e, muito menos, para levar em consideração as percepções do decisor.

O Balanço Patrimonial e a Demonstração de Resultado do Exercício são considerados, dentre os demonstrativos contábeis, os mais importantes divulgados pela 
Proposta de um modelo de avaliação de desempenho para apoiar decisões de investimento em empresas da Bovespa: A perspectiva da MCDA-C.

Sandro César Bortoluzzi, Sandra Rolim Ensslin, Leonardo Ensslin, Maurício Vasconcellos Leão

contabilidade das empresas. O Balanço Patrimonial evidencia a situação patrimonial da organização, e a Demonstração de Resultado do Exercício evidencia a situação econômica do empreendimento.

O relatório de administração tem o objetivo de divulgar informações relacionadas a questões sociais, fatos administrativos, investimentos em outras empresas, política de distribuição de dividendos e de reinvestimento de lucros (IUDÍCIBUS. et al., 2007). É um relatório obrigatório por lei, que deve evidenciar qualquer informação relevante que afete o desempenho econômico-financeiro da organização.

Após essa breve apresentação sobre as demonstrações contábeis e sobre o relatório de administração, contemplam-se, na seqüência, discussões inerentes à avaliação de desempenho econômico-financeiro propriamente dita. Esse tipo de avaliação é comumente realizado por meio de indicadores contábeis considerados tradicionais na literatura, que podem ser divididos em três grupos principais: Índices de Liquidez, Índices de Rentabilidade e Índices de Estrutura de Capital, sendo esses os indicadores utilizados neste trabalho.

Os Índices de Liquidez têm o objetivo de avaliar a capacidade de pagamento da empresa. De acordo com Assaf Neto (2006, p.189), "os indicadores de liquidez evidenciam a situação financeira de uma empresa frente a seus diversos compromissos financeiros". Percebe-se na literatura que o índice mais utilizado é o da liquidez corrente, que tem o objetivo de avaliar a capacidade de pagamento de curto prazo da empresa.

Os Índices de Rentabilidade têm o objetivo de analisar a empresa do ponto de vista econômico (ASSAF NETO, 2006). Para Matarazzo (1997, p.181), "os índices deste grupo mostram qual a rentabilidade dos capitais investidos, isto é, quanto rendeu os investimentos e, portanto, qual o grau de êxito econômico da empresa".

Os Índices de Estrutura de Capital são divididos em endividamento e imobilização. Segundo Carvalho (2007), os indicadores de endividamento são empregados para analisar se a empresa utiliza mais recursos de terceiros ou próprios, e também qual a relação de endividamento de curto prazo e de longo prazo. Conforme 
Proposta de um modelo de avaliação de desempenho para apoiar decisões de investimento em empresas da Bovespa: A perspectiva da MCDA-C.

Sandro César Bortoluzzi, Sandra Rolim Ensslin, Leonardo Ensslin, Maurício Vasconcellos Leão

Matarazzo (1997), o índice de imobilização procura demonstrar qual o grau de imobilização da empresa em relação ao patrimônio líquido e em relação aos recursos não-correntes.

Esses indicadores contábeis tradicionais são considerados monocritérios, pois levam em consideração apenas um indicador para avaliar o desempenho da organização, por exemplo, somente a liquidez, a rentabilidade ou algum indicador de endividamento. Essa afirmação foi confirmada no estudo de Lima (2003, p.106), no qual o autor salienta que "a ciência contábil tradicional utiliza-se, em geral, de métodos de avaliação com um único indicador, uma medida quantitativa de eficiência econômica". Nesse mesmo sentido, argumenta que desde o início do século $X X$ até meados de 1970, os instrumentos de gestão das empresas estavam alicerçados em modelos monocritérios pelos quais as decisões eram tomadas considerando apenas um indicador.

Ainda segundo o autor, percebe-se que tais modelos já não são suficientes para avaliar o desempenho da organização, uma vez que a complexidade envolvida é muito maior que a de algumas décadas atrás. Essa complexidade pode ser entendida pelas mudanças ocorridas nos sistemas produtivos, a alta tecnologia envolvida nos processos industriais (BARBOSA; GOMES, 2001). A partir da identificação dessas necessidades surgiram os métodos multicritérios, que levam em consideração simultaneamente mais de um indicador para avaliação do desempenho organizacional (WERNKE; BORNIA, 2001).

Os métodos multicritérios são considerados uma vertente da pesquisa operacional, que passou a ser utilizada em finanças no início na década de 1950, com a introdução da teoria de portfolio de Markovitz (1959). Conforme afirmam Wernke e Bornia (2001), nas décadas de 1970 e 1980 houve o surgimento de várias novas técnicas de avaliação por multicritérios visando ajudar os administradores a decidir de forma eficaz em relação a custos e também como uma forma de avaliar riscos e desempenho quando da análise de alternativas de investimentos. Desde então, essa área do conhecimento vem contribuindo com os problemas de tomada de decisão em 
Proposta de um modelo de avaliação de desempenho para apoiar decisões de investimento em empresas da Bovespa: A perspectiva da MCDA-C. Sandro César Bortoluzzi, Sandra Rolim Ensslin, Leonardo Ensslin, Maurício Vasconcellos Leão

outros campos de estudo em finanças, tais como investimentos em capital de risco, previsão de falência, planejamento financeiro, fusões e aquisições corporativas, avaliação de risco, etc. (SPRONK, 2005).

Diversos trabalhos foram realizados sobre avaliação de desempenho econômicofinanceiro nos últimos anos. Dentre eles, o trabalho de Braga e Marques (2000) analisou as medidas de avaliação de empresas na Companhia Paranaense de Energia - COPEL, com o objetivo de apresentar as limitações e complementaridade das metodologias; Perez e Fama (2003) apresentaram um artigo sobre os métodos de avaliação de empresas, com ênfase na avaliação por meio do fluxo de caixa descontado; Gasparetto (2004) discute o papel da contabilidade no provimento de informações para avaliação de desempenho; Saurin, Mussi e Cordioli (2000) estudaram o desempenho econômico das empresas estatais privatizadas utilizando as metodologias MVA (Market Value Added) e EVA ${ }^{\circledR}$. (Economic Value Added); Bressan, Braga e Bressan (2003) realizaram uma avaliação financeira das cooperativas de crédito rural do Estado de Minas Gerais, utilizando indicadores de estrutura de capital, solvência, despesas, rentabilidade e crescimento; Santos e Casa Nova (2005) utilizaram a metodologia Análise por Envoltória de Dados para analisar as demonstrações contábeis; Camargos e Barbosa (2005) realizaram um trabalho com o objetivo de analisar o desempenho econômico-financeiro nos processos de fusões do mercado brasileiro, utilizando a análise fundamentalista, por meio de indicadores contábeis considerados tradicionais pela literatura. Percebe-se que vários trabalhos estão sendo apresentados no intuito de fomentar a pesquisa sobre avaliação do desempenho econômico-financeiro, possibilitando um entendimento maior por parte dos pesquisadores e professores.

No que tange especificamente à MCDA-C, instrumento de intervenção utilizado no presente estudo, alguns trabalhos relacionados às finanças podem ser encontrados. Dentre eles citam-se: Lima (2003) propõe um método para construir modelos de avaliação de empresas de pequeno porte no Brasil, na perspectiva do investidor, com vistas a verificar o valor desse tipo de empresa como opção de negócio; Brandalise 
Proposta de um modelo de avaliação de desempenho para apoiar decisões de investimento em empresas da Bovespa: A perspectiva da MCDA-C. Sandro César Bortoluzzi, Sandra Rolim Ensslin, Leonardo Ensslin, Maurício Vasconcellos Leão

(2004) apresenta um modelo para aperfeiçoar o processo de faturamento realizado pela seção de contas a receber de uma gerência de contabilidade e controle financeiro (GECOF); Schnorrenberger (2005) sugere um modelo para identificar a avaliar os ativos tangíveis e intangíveis de uma empresa do setor de distribuição de energia elétrica com vistas a dar suporte ao gerenciamento da área econômico-financeira; e Lyrio et al. (2007) propõem a construção de um modelo para avaliar o grau de transparência das informações publicadas nas demonstrações financeiras de uma instituição pública de ensino superior brasileira. $O$ presente trabalho dá prosseguimento a esse tipo de pesquisa, abordando a avaliação de desempenho econômico-financeiro, de forma integrada, por meio da metodologia MCDA-C.

\section{METODOLOGIA DE PESQUISA}

Apresenta-se na seção de metodologia da pesquisa os seguintes aspectos: (i) enquadramento metodológico da pesquisa; e (ii) procedimentos para construção do modelo.

\subsection{Enquadramento Metodológico}

O presente estudo caracteriza-se como um estudo exploratório, o que, conforme Gil (2002), objetiva proporcionar maior familiaridade com o problema, para torná-lo mais explícito.

Para abordar o problema foi utilizado o método quali-quantitativo. Para Richardson (2008), método em pesquisa significa escolher os procedimentos para descrever e explicar os fenômenos. Segundo Ensslin. (2002), a pesquisa qualitativa pode apoiar-se em informações quantitativas de tal forma que os métodos sejam complementares e não incompatíveis. Esta pesquisa se caracteriza como uma pesquisa qualitativa e quantitativa. Qualitativa, pois tem o objetivo de aprofundar o conhecimento sobre o fenômeno, por meio da identificação dos critérios que irão compor o modelo de avaliação proposto; quantitativa, porque fará uso de ferramental matemático quando da tradução dos critérios, que, a princípio, se constituem em escalas ordinais e em escalas 
Proposta de um modelo de avaliação de desempenho para apoiar decisões de investimento em empresas da Bovespa: A perspectiva da MCDA-C.

Sandro César Bortoluzzi, Sandra Rolim Ensslin, Leonardo Ensslin, Maurício Vasconcellos Leão

cardinais; e, posteriormente, da identificação das taxas de substituição que servirão para integrar os critérios do modelo e permitir uma avaliação global de desempenho.

A fonte de coleta de dados é secundária, pois se buscou as informações nas demonstrações contábeis de uma empresa constituída sob a forma de sociedade anônima.

\subsection{Instrumento de Intervenção}

A Metodologia Multicritério de Apoio à Decisão - Construtivista (MCDA-C) selecionada para o presente estudo, baseada em um paradigma construtivista, busca estruturar o contexto decisional tendo em vista desenvolver modelos nos quais os decisores possam fundamentar suas decisões, a partir do que eles acreditam ser o mais adequado (ROY, 1990). Para atingir seu objetivo, a MCDA-C faz uso da atividade de apoio à decisão, composta de três fases: (i) Fase de Estruturação; (ii) Fase de Avaliação; e (iii) a Fase de Elaboração de Recomendações.

A Fase de Estruturação busca identificar e organizar os fatores relevantes a respeito da situação decisional. A estruturação se divide usualmente em três etapas: (i) Contextualização: abordagens soft - consiste em apresentar o ambiente onde se insere o problema; (ii) construção da estrutura hierárquica de valor - consiste em demonstrar de uma forma explicativa as preocupações referentes ao problema; e (iii) construção dos descritores - consiste na construção das escalas ordinais de mensuração.

A Fase de Avaliação se divide em duas etapas: (i) avaliação local das alternativas - construção de uma função de valor que represente as preferências do decisor em relação a um determinado critério; e (ii) avaliação global - agregação das avaliações locais em um critério único de síntese.

Finalmente, a Fase de Elaboração de Recomendações consiste na sugestão de ações potenciais para melhorar o desempenho em relação à situação atual. Este procedimento é baseado em duas análises: (i) verificação dos descritores que se encontram em nível comprometedor de desempenho; e (ii) verificação do potencial de contribuição de um descritor no desempenho global. 
Proposta de um modelo de avaliação de desempenho para apoiar decisões de investimento em empresas da Bovespa: A perspectiva da MCDA-C. Sandro César Bortoluzzi, Sandra Rolim Ensslin, Leonardo Ensslin, Maurício Vasconcellos Leão

\section{PROOPOSTA DE MOdelo de AVALIAÇÃo DE DESEMPENHO ECONÔMICO- FINANCEIRO}

Nesta seção, organizada conforme as fases do processo de apoio à decisão são apresentadas a construção do modelo, por meio da utilização da metodologia MCDA-C.

\subsection{Fase de estruturação}

O investidor que precisa tomar decisões em relação a investimentos em sociedades anônimas se depara com uma série de informações contábeis divulgadas pelas empresas. Essas informações são usualmente elaboradas para atender diferentes tipos de usuários, desde os próprios investidores, como também governo, sindicatos, associações, gestores internos, funcionários, entre outros. Dessa forma, não existe a preocupação de elaborar essas demonstrações personalizadas para cada tipo de usuário, dificultando, portanto, a interpretação dessas informações por parte dos investidores, o que pode acarretar em decisões equivocadas.

A partir do contexto apresentado, são identificados os seguintes atores envolvidos no processo:

- Decisor - um dos atores

- Facilitador - um dos atores

- Intervenientes - demais atores

Busca-se a construção de um modelo de avaliação de desempenho que permita a integração dos indicadores econômico-financeiros tradicionais por meio de um critério único de síntese, considerando as relações de causa e efeito entre os indicadores e o impacto destes no desempenho da organização como um todo. Pode-se dizer que a não-integração dos diversos indicadores econômico-financeiros prejudica a análise da organização por parte dos investidores e, consequentemente, a qualidade de suas decisões, uma vez que esta análise estará sendo realizada sem considerar a organização de uma forma sistêmica. 
Proposta de um modelo de avaliação de desempenho para apoiar decisões de investimento em empresas da Bovespa: A perspectiva da MCDA-C. Sandro César Bortoluzzi, Sandra Rolim Ensslin, Leonardo Ensslin, Maurício Vasconcellos Leão

Após a definição do problema e dos atores, parte-se para a definição do rótulo do problema. O rótulo é o enunciado do problema e deve retratá-lo de forma clara e objetiva, pois se propõe a delimitar o contexto decisório, focando nos aspectos relevantes relacionados ao problema que o facilitador irá apoiar a resolução (ENSSLIN; MONTIBELLER; NORONHA, 2001). O seguinte rótulo foi proposto para o trabalho: Avaliação de Desempenho Econômico-Financeiro Integrada.

Uma vez definidos o contexto decisional, os atores e o rótulo do problema, passa-se à construção do modelo propriamente dito. A primeira etapa desse processo diz respeito à definição dos Elementos Primários de Avaliação (EPAs), que se constituem nas primeiras preocupações que o decisor externaliza em relação à situação decisional em que se encontra (KENNEY, 1992). Uma vez reconhecidos, os EPAs são orientados à ação por meio da construção de um conceito para cada um deles, identificando um nível de excelência pretendido - pólo presente - e um nível mínimo aceitável pelo decisor - pólo oposto (ENSSLIN; MONTIBELLER; NORONHA, 2001; LYRIO et al., 2007). A transição do pólo presente para o pólo oposto do conceito se dá pela utilização do símbolo "...", que significa a expressão ao invés de. Como exemplo, cita-se o conceito 4 - monitorar a composição do endividamento da empresa ao invés de permitir que as atividades da empresa sejam financiadas por recursos de curto prazo. A Tabela 1 apresenta alguns EPAs identificados no estudo e os conceitos desenvolvidos a partir deles. 
Proposta de um modelo de avaliação de desempenho para apoiar decisões de investimento em empresas da Bovespa: A perspectiva da MCDA-C. Sandro César Bortoluzzi, Sandra Rolim Ensslin, Leonardo Ensslin, Maurício Vasconcellos Leão

Tabela 1 - Exemplos de Elementos Primários de Avaliação e Conceitos

\begin{tabular}{|c|c|c|c|c|}
\hline \multirow{2}{*}{\multicolumn{2}{|c|}{$\begin{array}{l}\text { Elementos Primários de Avaliação } \\
\text { (EPAs) }\end{array}$}} & \multicolumn{3}{|c|}{ Conceitos } \\
\hline & & \multirow{2}{*}{$\begin{array}{c}\text { Pólo Presente } \\
\text { Manter o índice de liquidez corrente o mais } \\
\text { próximo a } 1,10\end{array}$} & \multicolumn{2}{|r|}{ Pólo 0posto } \\
\hline 01 & Liquidez & & $\cdots$ & $\begin{array}{l}\text { Permitir que o índice de liquidez caia } \\
\text { abaixo de } 0,4 \text { ou suba acima de } 2,0\end{array}$ \\
\hline 02 & Rentabilidade & Aumentar a rentabilidade sobre o Ativo e o P.L. & $\ldots$ & Ter rentabilidade acima de zero $\%$ \\
\hline 03 & Imobilização do Capital & Gerenciar o grau de imobilizaçẫo da empresa & $\ldots$ & Nẫo possuir instrumentos de controle \\
\hline 04 & Endividamento da Empresa & $\begin{array}{c}\text { Monitorar a composiçẫo do endividamento da } \\
\text { empresa }\end{array}$ & $\cdots$ & $\begin{array}{c}\text { Permitir que as atividades da empresa } \\
\text { sejam financiadas por recursos de curto } \\
\text { prazo }\end{array}$ \\
\hline 05 & Patrimônio & \multicolumn{3}{|c|}{ SUPRIMIDO } \\
\hline 06 & Margem de Lucro & Aumentar o máximo possivel a margem líquida & $\ldots$ & Deixar a empresa ter prejuizo \\
\hline 07 & Financiamento de Terceiros & $\begin{array}{l}\text { Buscar com que cerca de metade das fontes de } \\
\text { financiamento sejam de terceiros }\end{array}$ & $\cdots$ & $\begin{array}{l}\text { Ter pouco capital de terceiros ou capital } \\
\text { de terceiros financiando prejuizos da } \\
\text { empresa }\end{array}$ \\
\hline
\end{tabular}

Fonte: Elaboração própria.

Após a construção dos conceitos, estes são agrupados em áreas de preocupação e hierarquizados de acordo com suas relações de causa e efeito em mapas de relações meios-fins (EDEN, 1988). Um mapa de relações meios-fins pode ser utilizado para desenvolver conhecimento a respeito de uma realidade, apresentando as variáveis que descrevem um fenômeno e representando as relações causais existentes entre elas. Dessa forma, pode ajudar os tomadores de decisão a identificar possíveis ações que gerem efeitos positivos no desempenho (MONTIBELLER; BELTON, 2007; MONTIBELLER et al., 2007).

Com os mapas de relações meios-fins construídos, é possível desenvolver uma segunda estrutura, conhecida como estrutura arborescente. Nessa nova estrutura, as áreas de preocupações identificadas no mapa conduzem à seleção de Pontos de Vista Fundamentais (PVFs), desdobrados em Pontos de Vista Elementares (PVEs), até um nível possível de ser mensurado (ENSSLIN; MONTIBELLER; NORONHA, 2001). 
Proposta de um modelo de avaliação de desempenho para apoiar decisões de investimento em empresas da Bovespa: A perspectiva da MCDA-C. Sandro César Bortoluzzi, Sandra Rolim Ensslin, Leonardo Ensslin, Maurício Vasconcellos Leão

Lyrio

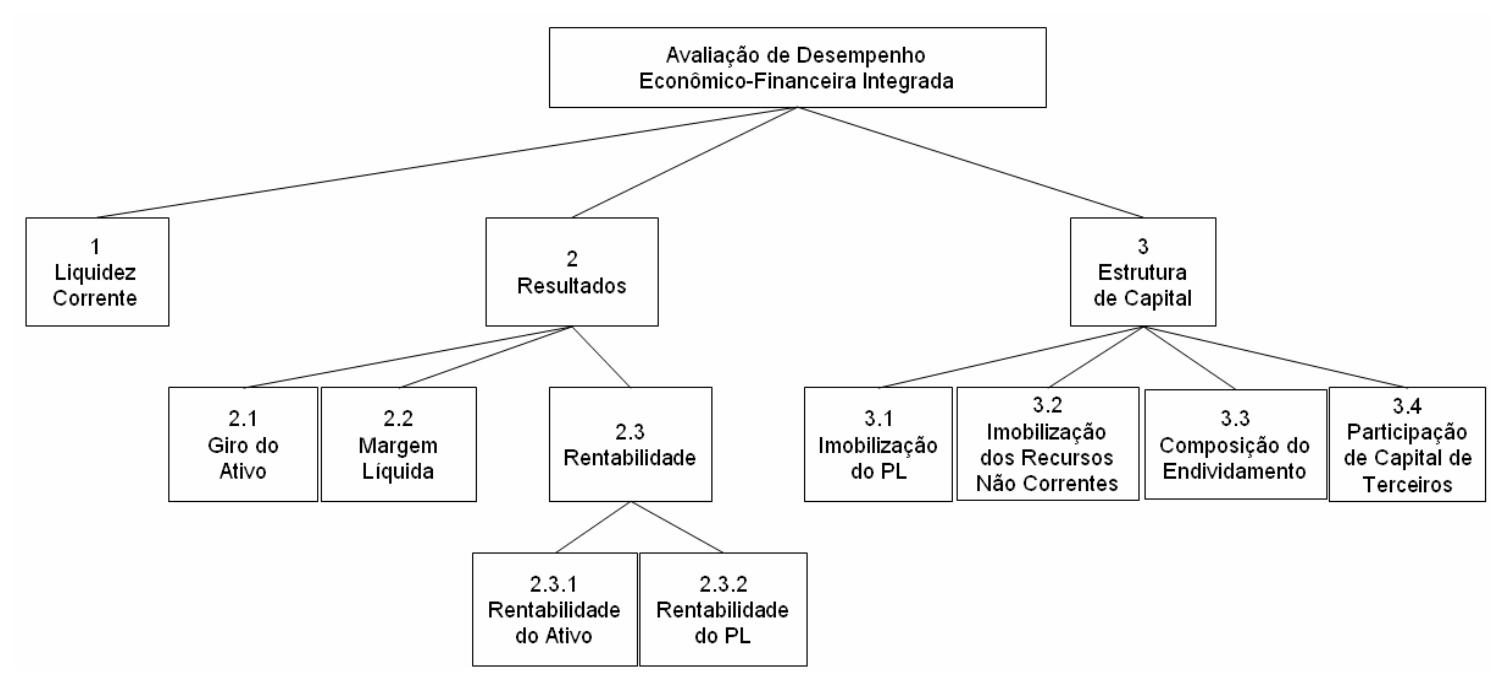

Figura 1 - Estrutura Arborescente

A última etapa da fase de estruturação se refere ao processo para construir os descritores que irão mensurar qualitativamente o desempenho em cada critério de análise. Observe-se pelo

Quadro 1, referente ao descritor 2.3.2 - Rentabilidade do P.L., que o descritor é composto por uma escala - como é medido o critério; um conjunto de níveis - possíveis impactos das ações; e dois níveis de referência, Bom e Neutro - dentre os quais os impactos são considerados como em nível de mercado. Os níveis acima do nível Bom são considerados benchmarking; por outro lado, os níveis abaixo do nível neutro são considerados comprometedores, sendo penalizados no modelo com pontuação negativa (ENSSLIN; MONTIBELLER; NORONHA, 2001). 
Proposta de um modelo de avaliação de desempenho para apoiar decisões de investimento em empresas da Bovespa: A perspectiva da MCDA-C. Sandro César Bortoluzzi, Sandra Rolim Ensslin, Leonardo Ensslin, Maurício Vasconcellos Leão

\begin{tabular}{|c|c|l|}
\hline \multicolumn{2}{|c|}{ Descritor 2.3.2: Rentabilidade sobre o P.L. } \\
\hline $\begin{array}{c}\text { Niveis de } \\
\text { Impacto }\end{array}$ & $\begin{array}{c}\text { Niveis de } \\
\text { Referência }\end{array}$ & Descrição \\
\hline N5 & & Acima de $30 \%$ \\
\hline N4 & BOM & Acima de $20 \%$ a $30 \%$ \\
\hline N3 & & Acima de $10 \%$ a $20 \%$ \\
\hline N2 & NEUTRO & Acima de $0 \%$ a $10 \%$ \\
\hline N1 & & $0 \%$ ou neqativo \\
\hline Escala: (Lucro Líquido / Patrimônio Líquido) * 100 \\
\hline
\end{tabular}

Quadro 1 - Exemplo de descritor

Uma vez construídos os descritores, que até este momento se constituem em escalas qualitativas e ordinais, está finalizada a fase de estruturação. Passa-se então à fase de avaliação.

\subsection{Fase de Avaliação}

Independente do arcabouço metodológico multicritério escolhido para análise, a fase de avaliação se divide em duas etapas: (i) proceder a uma avaliação local - que representa as preferências do decisor em relação a um determinado critério; e (ii) proceder a uma avaliação global - que considera as avaliações locais e as agrega em um critério único de síntese, considerando algumas informações interponto de vista (BANA; COSTA et al., 1999).

Para proceder à avaliação local, devem-se transformar as escalas qualitativas, desenvolvidas para cada um dos descritores, em escalas quantitativas. Para tanto, optou-se por utilizar o software MACBETH (Measuring Attractiveness by Categorical Based Evaluation Technique). Este software permite que se atribua notas a cada nível de um descritor, solicitando ao decisor que determine semanticamente qual a perda percebida na passagem de um nível para outro imediatamente inferior (BANA; COSTA; VANSNICK, 1997). Vale ressaltar que aos níveis "Bom" e "Neutro" determinados para cada descritor, é atribuída a pontuação 100 e 0 , respectivamente. Por meio de 
Proposta de um modelo de avaliação de desempenho para apoiar decisões de investimento em empresas da Bovespa: A perspectiva da MCDA-C.

Sandro César Bortoluzzi, Sandra Rolim Ensslin, Leonardo Ensslin, Maurício Vasconcellos Leão

programação linear, o software gera uma função de valor para o descritor, conforme observado na

Figura 2 e na Figura 3.

\begin{tabular}{|c|c|c|c|c|c|c|c|}
\hline \multicolumn{8}{|c|}{ 2.3.2 Rentabilidade do P. L. } \\
\hline 畻 & N5 & N4 & N3 & N2 & N1 & $\begin{array}{c}\begin{array}{c}\text { Current } \\
\text { scale }\end{array} \\
\end{array}$ & extreme \\
\hline N5 & no & moderate & moderate & strong & v. strong & 130 & צ. strong \\
\hline N4 & & no & moderate & strong & v. strong & 100 & strong \\
\hline N3 & & & no & strong & v. strong & 70 & moderate \\
\hline N2 & & & & no & v. strong & $\mathbf{0}$ & veru weak \\
\hline N1 & & & & & no & -140 & no \\
\hline \multicolumn{8}{|c|}{ Consistent judgements } \\
\hline 围 & & $801+8$ & 困比渞 & $H$ & 연 & & \\
\hline
\end{tabular}

Figura 2 - Escala gerada pelo software M-MACBETH

Ainda em relação à Figura 3, o gráfico evidencia a perda percebida pelo decisor no decorrer da passagem de um nível para outro. Nesse caso, para o decisor, a perda de atratividade percebida na passagem de um nível para outro se acentua na medida em que se aproxima do nível neutro - momento em que a rentabilidade do P.L. atinge níveis iguais ou inferiores a 10\%. Essa análise está de acordo com as percepções do decisor, que acredita que o importante, nesse caso, é "a empresa não dar prejuízo".

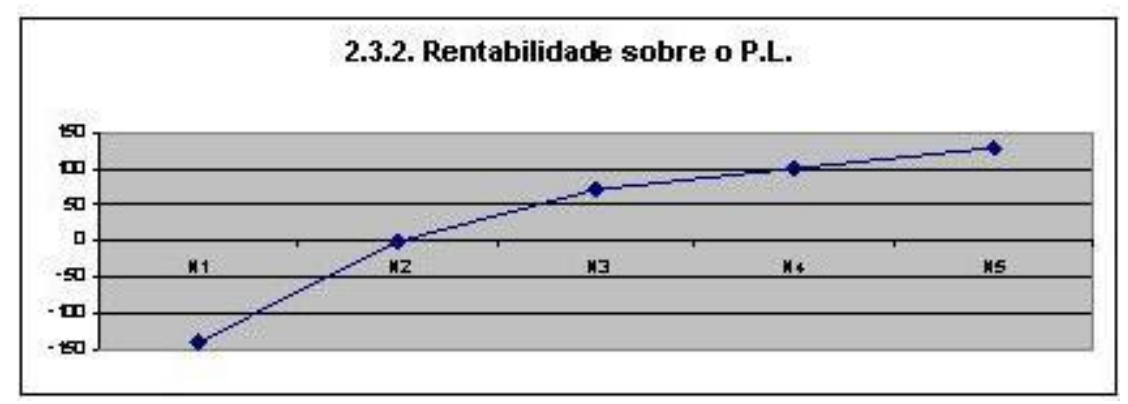

Figura 3 - Função de Valor para o Descritor 2.3.2 - Rentabilidade do P.L.

Para proceder à avaliação global, mais uma vez optou-se pelo software MACBETH, dessa vez utilizando sua função weighting. Esta etapa consiste na 
Proposta de um modelo de avaliação de desempenho para apoiar decisões de investimento em empresas da Bovespa: A perspectiva da MCDA-C.

Sandro César Bortoluzzi, Sandra Rolim Ensslin, Leonardo Ensslin, Maurício Vasconcellos Leão

construção de taxas de substituição que informam a importância relativa de cada critério no modelo como um todo. Para tanto, em primeiro lugar, realiza-se uma ordenação preferencial dos Pontos de Vista (PVs), por meio de uma matriz de ordenação (ROBERTS, 1979), conforme demonstrado no Quadro 2.

\begin{tabular}{|l|c|c|c|c|c|}
\hline PONTOS DE VISTA FUNDAMENTAIS & 1 & 2 & 3 & TOTAL & Ordem \\
\hline 1. Liquidez Corrente & & 0 & 1 & 1 & $2^{\circ}$ \\
\hline 2. Resultados & 1 & & 1 & 2 & $1^{\circ}$ \\
\hline 3. Estrutura de Capital & 0 & 0 & & 0 & $3^{\circ}$ \\
\hline
\end{tabular}

Quadro 2 - Matriz de Roberts

Em seguida, o procedimento é semelhante ao utilizado para determinar as escalas dos descritores, sendo solicitado ao decisor que realize novamente uma comparação da atratividade percebida entre os PVs. Nesta etapa, o software introduz um PV com todos os impactos no nível neutro, a fim de evitar que um PV real receba uma taxa zero. A Figura 4 apresenta as taxas de substituição geradas para os PVFs do modelo proposto. Vale ressaltar que esse mesmo procedimento foi utilizado para determinar as taxas de substituição em todos os PVs do modelo. Uma vez encontradas as taxas de substituição, o modelo está construído.

\begin{tabular}{|c|c|c|c|c|c|c|}
\hline \multicolumn{7}{|c|}{ Wy Weighting (Avaliação de Desempenho Economico-Financeira) X } \\
\hline 贯 & [2. Result. ] & [1. L. C. ] & [3. E. C. ] & [ all lower ] & $\begin{array}{l}\text { Current } \\
\text { scale }\end{array}$ & extreme \\
\hline [2. Result. ] & no & strong & strong & positive & 64.00 & Y. strong \\
\hline [1. L. C.] & & no & weak & positive & 27.00 & strong \\
\hline [3. E. C.] & & & no & nosit & 900 & moderate \\
\hline [ all lower ] & & & & mo & 000 & weak \\
\hline \multicolumn{6}{|c|}{ Consistent judgements } & very weak \\
\hline $\begin{array}{l}\text { 曾 } \\
\text { OK? }\end{array}$ & 8 & 형 典 & fWuch & DIFF & ? 咺? & \\
\hline
\end{tabular}

Figura 4 - Taxas de substituição geradas pelo software M-MACBETH Fonte: M-MACBETH v. 1.1, 2005 
Proposta de um modelo de avaliação de desempenho para apoiar decisões de investimento em empresas da Bovespa: A perspectiva da MCDA-C. Sandro César Bortoluzzi, Sandra Rolim Ensslin, Leonardo Ensslin, Maurício Vasconcellos Leão

Por fim, para conhecer o desempenho econômico-financeiro global da organização, procede-se a uma agregação das avaliações locais por meio da seguinte equação:

$$
\begin{gathered}
\mathrm{n}(\mathrm{a})=\sum w_{\mathrm{i}} \mathrm{X} v_{\mathrm{i}}(\mathrm{a}) \\
i=1
\end{gathered}
$$

onde:

$\mathrm{V}(\mathrm{a})$ = valor do Desempenho econômico-financeiro Global;

$\mathrm{V}^{1}(\mathrm{a}), \mathrm{V}^{2}(\mathrm{a}), \ldots \mathrm{Vn}(\mathrm{a})$ = valor parcial do desempenho econômico-financeiro nos critérios $1,2, \ldots \mathrm{n}$;

$\mathrm{W}^{1}, \mathrm{~W}^{2}, \ldots \mathrm{W}_{\mathrm{n}}=$ taxas de substituição nos critérios $1,2, \ldots \mathrm{n}$;

$\mathrm{n}=\mathrm{n}^{\circ}$ de critérios do modelo.

\subsection{Fase de Elaboração de Recomendações}

A última fase do processo de apoio à decisão se destina à sugestão de ações potenciais que visam melhorar a situação da organização em relação à situação atual. Esse processo é realizado por meio de uma análise do perfil de desempenho, na qual se buscam identificar os descritores cujo desempenho está aquém das expectativas ou os descritores que possuem um potencial de contribuição global superior. Além disso, nesta fase é necessário realizar uma análise de sensibilidade no modelo de avaliação, a fim de testar sua robustez. Neste estudo, optou-se por desenvolver esta etapa no decorrer da aplicação do modelo.

\section{APLICAÇÃO DO MODELO: POSITIVO INFORMÁTICA S.A.}

Com o objetivo de testar a aplicabilidade do modelo para que o investidor possa tomar a decisão que melhor represente suas percepções, foi escolhida de forma aleatória uma empresa do setor de informática. As demonstrações contábeis foram 
Proposta de um modelo de avaliação de desempenho para apoiar decisões de investimento em empresas da Bovespa: A perspectiva da MCDA-C. Sandro César Bortoluzzi, Sandra Rolim Ensslin, Leonardo Ensslin, Maurício Vasconcellos Leão

selecionadas no site da BOVESPA, referentes aos períodos de 2006 e de 2007. Utilizou-se o software Sistema de Divulgação Externa (DIVEXT), fornecido pelo site e, na seqüência, exportadas e tratadas em Excel. O tratamento dado às informações se refere ao cálculo dos indicadores contábeis referentes à empresa em estudo. Na tabela 2, apresentam-se os índices da empresa Positivo Informática S.A. Esta tabela apresenta cada um dos indicadores, bem como seus índices de desempenho a cada ano, referentes os anos de 2006 e de 2007.

Tabela 2 - Indicadores contábeis tradicionais da Empresa

\begin{tabular}{|c|c|c|c}
\hline Descritores & Escalas & \multicolumn{2}{c}{ Positivo } \\
\cline { 3 - 4 } & 2006 & $\mathbf{2 0 0 7}$ \\
\hline Liquidez Corrente & Ativo Circulante / Passivo Circulante & 2,16 & 2,21 \\
\hline Giro do Ativo & Vendas Líquidas / Ativo Total & 1,77 & 1,68 \\
\hline Margem Liquida & Lucro Líquido / Vendas Líquidas X 100 & $2 \%$ & $4 \%$ \\
\hline Rentabilidade sobre o Ativo & Lucro Líquido / Ativo Total X 100 & $4 \%$ & $7 \%$ \\
\hline $\begin{array}{c}\text { Rentabilidade sobre o Patrimônio } \\
\text { Líquido }\end{array}$ & $\begin{array}{c}\text { Lucro Líquido / Patrimônio Líquido médio X } \\
100\end{array}$ & $9 \%$ & $15 \%$ \\
\hline Participação de Capitais de Terceiros & $\begin{array}{c}\text { Capitais de Terceiros / Patrimônio Líquido X } \\
100\end{array}$ & $83 \%$ & $78 \%$ \\
\hline Composição do Endividamento & $\begin{array}{c}\text { Passivo Circulante Capitais de Terceiros X } \\
100\end{array}$ & $95 \%$ & $97 \%$ \\
\hline Imobilização do Patrimônio Líquido & $\begin{array}{c}\text { Ativo Permanente / Patrimônio Líquido X } \\
100\end{array}$ & $11 \%$ & $10 \%$ \\
\hline $\begin{array}{c}\text { Imobilização dos Recursos não } \\
\text { Correntes }\end{array}$ & $\begin{array}{c}\text { Ativo Permanente / Patrimônio Líquido + } \\
\text { Exígivel a Longo Prazo X 100 }\end{array}$ & $10 \%$ & $10 \%$ \\
\hline
\end{tabular}

Verifica-se, na Tabela 2 que as informações produzidas pelo cálculo dos índices contábeis considerados tradicionais pela literatura não são suficientes para identificar com clareza a situação da empresa em análise. Por essa Tabela não é possível determinar qual indicador tem maior importância para o decisor, bem como determinar um valor global do desempenho da organização.

Pretende-se obter uma avaliação global do desempenho econômico-financeiro da empresa integrando estes indicadores em um critério único de síntese por meio da aplicação do modelo proposto. Nesta aplicação, cada um desses índices será impactado no modelo de acordo com o nível de desempenho no qual ele se enquadra. Uma vez que todos os índices tenham sido impactados no modelo, é possível identificar 
Proposta de um modelo de avaliação de desempenho para apoiar decisões de investimento em empresas da Bovespa: A perspectiva da MCDA-C. Sandro César Bortoluzzi, Sandra Rolim Ensslin, Leonardo Ensslin, Maurício Vasconcellos Leão

um valor, bem como um perfil do desempenho global da organização. A Figura 5 e a Figura 6 apresentam o perfil de desempenho econômico-financeiro da Positivo Informática S.A. em 2006 e 2007, respectivamente.

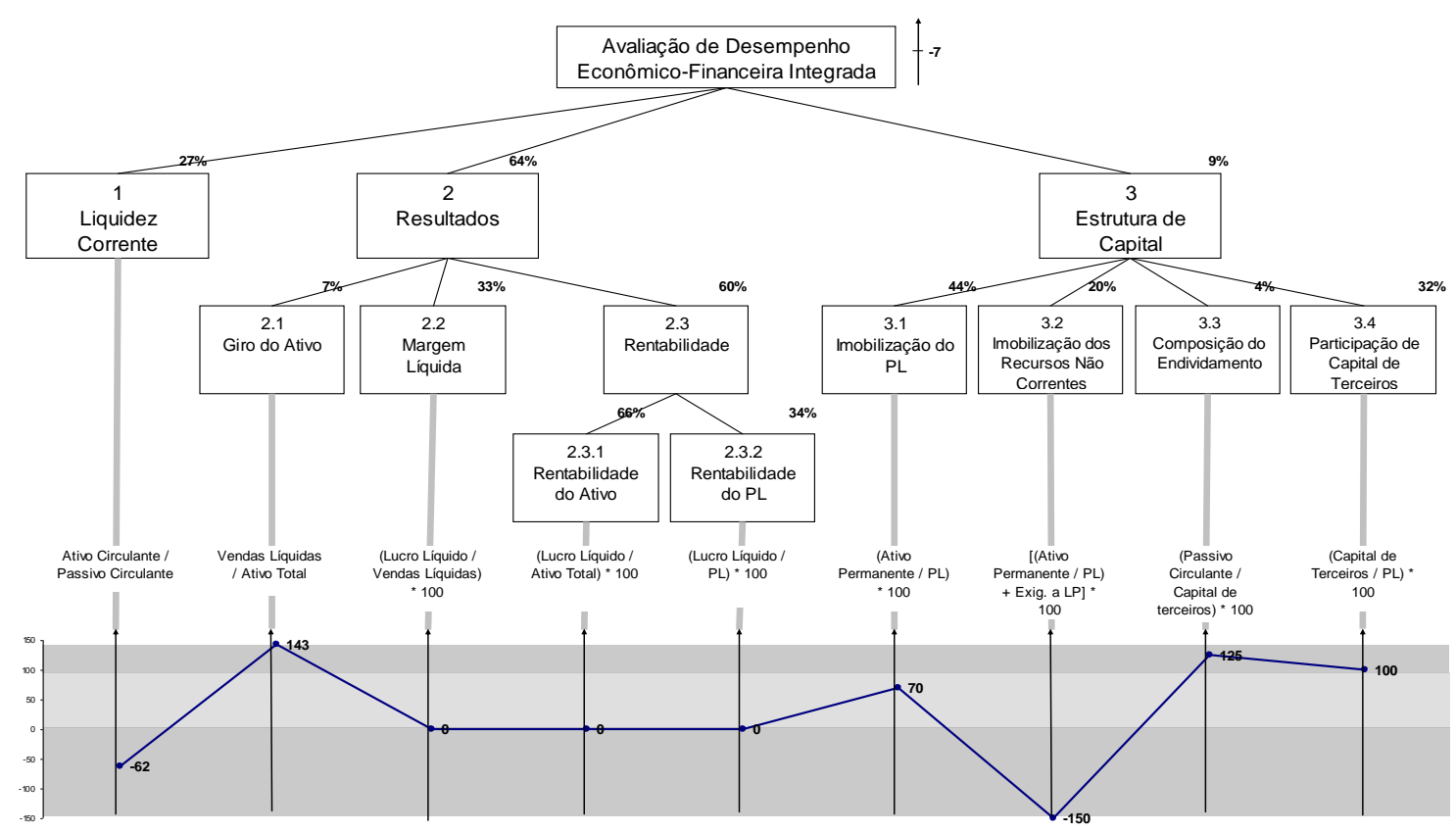

Figura 5 - Perfil de desempenho econômico-financeiro da Positivo Informática S.A. (ano 2006)

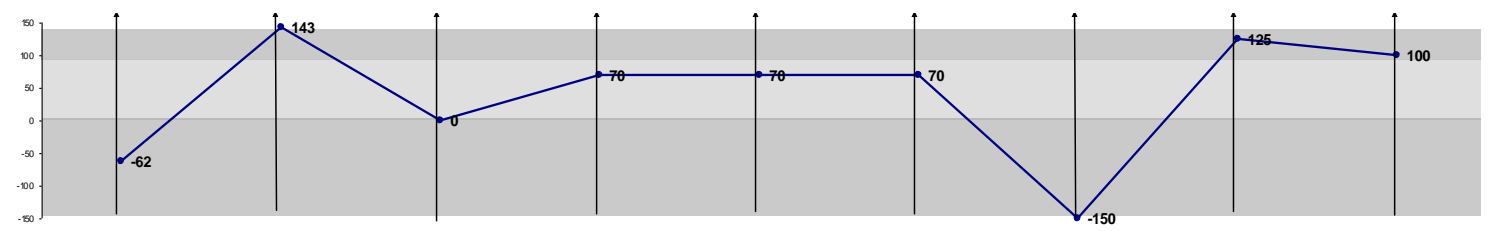

Figura 6 - Perfil de desempenho econômico-financeiro da Positivo Informática S.A. (ano 2007)

Neste estudo, a Positivo Informática S.A. obteve -7 pontos em 2006, e 20 pontos em 2007 (conforme equação apresentada em 4.2). Esse desempenho se configurou como um desempenho em nível de mercado, apesar de pouco competitivo, haja vista que um nível de desempenho considerado bom equivale a 100 pontos. Pelo modelo, pode-se dizer que, em 2006 e em 2007, o desempenho global da organização foi prejudicado, principalmente, pelo nível de desempenho comprometedor apresentado no descritor 1 - Liquidez Corrente, e no descritor 3.2 - Imobilização dos recursos não- 
Proposta de um modelo de avaliação de desempenho para apoiar decisões de investimento em empresas da Bovespa: A perspectiva da MCDA-C. Sandro César Bortoluzzi, Sandra Rolim Ensslin, Leonardo Ensslin, Maurício Vasconcellos Leão

correntes. A melhora no desempenho de 2006 para 2007 foi percebida principalmente pelo nível de desempenho dos descritores 2.3.1 - Rentabilidade do Ativo e Rentabilidade do PL.

\subsection{Relatório de Administração da Positivo}

O Relatório de Administração da Positivo S.A. traz uma mensagem otimista aos investidores e destaca principalmente a liderança de mercado, o aumento significativo nas vendas e perspectiva futura por meio de investimentos em parque industrial, consolidação da marca e em pesquisa e desenvolvimento.

Mesmo apresentando perspectivas de crescimento e demonstrando ter potencial de geração de valor, a empresa é considerada pouco competitiva na perspectiva do decisor, apesar de apresentar nível de mercado para a maioria dos indicadores. A pouca competitividade, segundo a percepção do decisor, se deve à empresa apresentar liquidez em nível comprometedor, pois um índice de liquidez acima de 2 é considerado pelo decisor como uma atitude muito conservadora por parte da empresa, haja vista que existe um grande volume de recursos "parado" no caixa, sendo que poderiam ser investidos na atividade da empresa e assim gerar melhores resultados. Os principais destaques do relatório de administração da empresa estão elencados a seguir, sendo que estes apresentaram reflexos no desempenho da empresa: (i) recorde de venda de computadores no Brasil, mais de 1 milhão de computadores vendidos; (ii) ampliação da planta da unidade de Curitiba e abertura de duas novas unidades produtivas: uma, em Manaus/Amazônia, e outra, em Ilhéus/Bahia; (iii) investimentos consideráveis em pesquisa e desenvolvimento; (iv) investimento maior que 100 milhões na consolidação da marca; ( $v$ ) aumento considerável na receita da empresa.

\section{CONSIDERAÇÕES FINAIS}

O estudo aqui relatado teve com objetivo propor um modelo para avaliação de desempenho econômico-financeiro, que considere os indicadores contábeis tradicionais 
Proposta de um modelo de avaliação de desempenho para apoiar decisões de investimento em empresas da Bovespa: A perspectiva da MCDA-C.

Sandro César Bortoluzzi, Sandra Rolim Ensslin, Leonardo Ensslin, Maurício Vasconcellos Leão

permitindo uma avaliação pontual e, posteriormente, uma integração desses indicadores para possibilitar uma avaliação global do desempenho da organização, considerando as percepções de um decisor no momento de seleção de empresas a investir. A pergunta de pesquisa que orientou o trabalho é transcrita e devidamente respondida a seguir: Como integrar as percepções de um decisor em um modelo de avaliação de desempenho com vistas a apoiar a seleção de empresas a investir?

A resposta à pergunta de pesquisa se deu por meio da construção do modelo, no qual a integração dos indicadores foi realizada por meio de interações com o decisor, considerando as preocupações que este levava em consideração no momento de selecionar uma empresa para investir. A metodologia utilizada permitiu identificar e organizar essas preocupações e, posteriormente, mensurá-las de forma integrada, fazendo com que a decisão de investimento seja mais adequada aos valores do decisor. Com a aplicação do modelo na Positivo Informática S.A. foi possível chegar a um valor global do desempenho econômico-financeiro dessa empresa (-7 pontos em 2006 e 20 pontos em 2007), cumprindo o objetivo de apoiar o decisor no momento de tomar a decisão. Além de determinar um valor global do desempenho da empresa, 0 modelo foi capaz de traçar um perfil desse desempenho, o que proporcionou uma melhor visualização da situação da empresa e uma percepção da importância relativa de cada descritor.

Em relação ao relatório de administração, percebe-se que algumas informações são destacadas, tendo como principal objetivo passar uma mensagem de otimismo para os investidores. Apesar de ser um relatório obrigatório por lei, as informações que devem constar no relatório não são claras. Sendo assim, as empresas destacam as informações que lhes são pertinentes. Com a construção e aplicação do modelo, o decisor tem condições de comparar as informações divulgadas no relatório da administração com os resultados da avaliação e verificar a situação da empresa de acordo com suas perspectivas. No caso do presente estudo, ficou evidenciado que, apesar de o relatório da administração apresentar uma situação otimista, o resultado da aplicação do modelo não mostrou o mesmo, o que evidencia que a empresa não se 
Proposta de um modelo de avaliação de desempenho para apoiar decisões de investimento em empresas da Bovespa: A perspectiva da MCDA-C.

Sandro César Bortoluzzi, Sandra Rolim Ensslin, Leonardo Ensslin, Maurício Vasconcellos Leão

encontra em situação confortável, no que tange aos critérios considerados importantes pelo decisor no momento de seleção de uma empresa a investir.

Uma vez que o resultado apresentado pela empresa em estudo diz respeito à forma como um investidor específico a vê, esses resultados, bem como o modelo propriamente dito, não devem ser generalizados. Portanto, sugere-se, como recomendação para futura pesquisa, aplicar o estudo em outras situações, considerando outros decisores, com a finalidade de adequar a avaliação a cada situação específica.

\section{REFERÊNCIAS}

ASSAF NETO, A. (2006). Estrutura e análise de balanços: um enfoque econômicofinanceiro. (8 ed.). São Paulo. Atlas, 376 p.

BANA e COSTA, C. A.; ENSSLIN, L.; CORREA, E. C.; VANSNICK, J. C. (1999). Decision Suport Systems in Action: Integrated Aplication in a Multicriteria Decision Aid Process. European Journal of Operational Research, v. 113, n. 2, p. 315-335.

BANA e COSTA, C. A.; VASNICK, J. C. (1997). Applications of the MACBETH approach in the framework of an additive aggregation model. Journal of Multi-criteria Decision Analysis, v. 6, n. 2, p. 107-114.

BARBOSA, J. G. P.; GOMES, J. S. (2001). Um estudo exploratório do controle gerencial de ativos e recursos intangíveis (capital intelectual) em empresas brasileiras. In: EnANPAD, 25, Campinas. Anais... Campinas.

BRAGA, R.; MARQUES, J. I. V. C. (2000). Medidas de avaliação de empresas: uma evidência de suas relevâncias no caso da companhia paranaense de energia - COPEL. Caderno de Pesquisa em Administração, v. 7, n. 4.

BRANDALISE, K. C. D. A. (2004). Metodologia de apoio à decisão construtivista para aperfeiçoamento de processos de faturamento em uma organização. (Dissertação de Mestrado). Universidade Federal de Santa Catarina - UFSC, Florianópolis.

BRESSAN, V. G. F.; BRAGA, M. J.; BRESSAN, A. A. (2003). Avaliação financeira de cooperativas de crédito rural do Estado de Minas Gerais. Caderno de Administração Rural, v. 5, n. 2.

CAMARGOS, M. A.; BARBOSA, F. D. (2005). Análise do desempenho econômico- 
Proposta de um modelo de avaliação de desempenho para apoiar decisões de investimento em empresas da Bovespa: A perspectiva da MCDA-C. Sandro César Bortoluzzi, Sandra Rolim Ensslin, Leonardo Ensslin, Maurício Vasconcellos Leão

financeiro e da criação de sinergias em processos de fusão e aquisição do mercado brasileiro ocorrido entre 1995 e 1999. Caderno de Pesquisas em Administração, v. 12, n. 2.

CARVALHO, J. R.M. (2007). Medição de Desempenho Empresarial: um estudo nas organizações do setor salineiro no Estado do Rio Grande do Norte. 103 f. (Dissertação de Mestrado). Programa Multiinstitucional e Inter-Regional de Pós-Graduação em Ciências Contábeis, Natal.

EDEN, C. Cognitive mapping. (1988). European Journal of Operational Research, v. 36, p. 01-13.

EDEN, C.; ACKERMANN, F.; CROPPER, S. (1992). The analysis of Cause Maps. Journal of Management Studies, v. 29, n. 3, p. 369-389.

ENSSLIN, L.; MONTIBELLER, G.; NORONHA, S. M. (2001). Apoio à decisão: metodologia para estruturação de problemas e avaliação multicritério de alternativas. Florianópolis: Insular.

ENSSLIN, S. R. (2002). A incorporação da perspectiva sistêmico-sinergética na metodologia MCDA-C-Construtivista: uma ilustração de implementação. 461 f. (Tese de Doutorado). Universidade Federal de Santa Catarina - UFSC, Florianópolis.

GASPARETTO, V. (2004). O papel da contabilidade no provimento de informações para avaliação de desempenho empresarial. Revista Contemporânea de Contabilidade, v. 1, n. 2.

GIL, A. C. (2002). Como elaborar projetos de pesquisa. (4 ed.). São Paulo: Atlas, 176 p.

HAIR JR, J. F.; R. E. ANDERSON; R. L. TATHAM e W. C. BLACK. (1998). Multivariate Data Analysis. (5th ed.). Upper Saddle River: Prentice Hall, 730p.

IGARASHI, D.C.C.; ENSSLIN,S. R.; ENSSLIN,L.; PALADINI, E.P. (2008). A qualidade do ensino sob o viés da avaliação de um programa de pós-graduação em contabilidade: proposta de estruturação de um modelo híbrido. RAUSP - Revista de Administração da Universidade de São Paulo. São Paulo. V.43, n.2, p.117-137.

IUDÍCIBUS, S.; MARTINS, E.; GELBCKE, E. R. (2007). Manual de Contabilidade das sociedades por ações: aplicável às demais sociedades. (7 ed.). São Paulo: Atlas.

KEENEY, R. L. (1992). Value focused-thinking: a path to creative decision-making. Cambridge: Harvard Univ. Press.

LIMA, M. V. A. (2003). Metodologia construtivista para avaliar empresas de pequeno 
Proposta de um modelo de avaliação de desempenho para apoiar decisões de investimento em empresas da Bovespa: A perspectiva da MCDA-C. Sandro César Bortoluzzi, Sandra Rolim Ensslin, Leonardo Ensslin, Maurício Vasconcellos Leão

porte no Brasil, sob a ótica do investidor. 2003. 382 f. (Tese de Doutorado). Universidade Federal de Santa Catarina - UFSC, Florianópolis.

LYRIO, M. V. L.; BROTTI, V.; ENSSLIN, S. R.; ENSSLIN, L. (2007). Proposta de um modelo para avaliar o grau de transparência das demonstrações financeiras publicadas por uma instituição pública de ensino superior brasileira: a abordagem da metodologia multicritério de apoio à decisão - construtivista. In: 5 INTERNATIONAL CONFERENCE OF IBEROAMERICAN ACADEMY OF MANAGEMENT, Santo Domingo. Anais... Santo Domingo, República Dominicana.

MATARAZZO, D. C. (1997). Análise financeira de balanços: abordagem básica e gerencial. (4 ed.). São Paulo: Atlas, 463 p.

MONTIBELLER, G.; BELTON, V. (2007). Qualitative operators for reasoning maps: evaluating multi-criteria options with networks of reasons. European Journal of Operational Research. V. In Press, Corrected Proof.

MONTIBELLER, G.; BELTON, V.; ACKERMANN, F.; ENSSLIN, L. (2007). Reasoning maps for decision aid: an integrated approach for problem-structuring and multi-criteria evaluation. Journal of the Operational Research Society. 59, p. 575-589.

PEREZ, M. M.; FAMÁ, R. (2003). Métodos de avaliação de empresas e o balanço de determinação. Caderno de Pesquisa em Administração, v. 10, n. 4.

RICHARDSON, R. J. (2008). Pesquisa social: métodos e técnicas. (3 ed.). São Paulo: Atlas.

ROBERTS, F. S. Measurement Theory. In: ROTA, G. C. (Ed.) (1979). Encyclopedia of mathematics and its applications, v. 7, London: Addison-Wesley Publishing Company.

ROY, B. Decision-aid and decision making. In: BANA e COSTA (Ed.) (1990). Readings in Multiple Criteria Decision Aid, Berlin: Springer, p. 17-35.

SANTOS, A.; CASA NOVA, S. P. C. (2005). Proposta de um modelo estruturado de análise de demonstrações contábeis. RAE-Eletrônica, v. 4, n. 1.

SAURIN, V.; MUSSI, C. C.; CORDIOLI, L. A. (2000). Estudo do desempenho econômico das empresas estatais privatizadas com base no MVA e no EVA. Caderno de Pesquisa em Administração, v. 1, n. 11.

SCHNORRENBERGER, D. (2005). Identificando e avaliando os ativos tangíveis e intangíveis de uma organização visando seu gerenciamento: uma ilustração na área econômico-financeira. 225 f. (Tese de Doutorado). Universidade Federal de Santa Catarina - UFSC, Florianópolis. 
Proposta de um modelo de avaliação de desempenho para apoiar decisões de investimento em empresas da Bovespa: A perspectiva da MCDA-C. Sandro César Bortoluzzi, Sandra Rolim Ensslin, Leonardo Ensslin, Maurício Vasconcellos Leão

SPRONK, J. (2005). Multicriteria decision aid/analysis in finance. In: FIGUEIRA, J.; SALVATORE, G.; MATTHIAS, E. (Ed.). Multiple criteria decision analysis: state of the art surveys, New York: Springer, p. 799-857.

WERNKE, R.; BORNIA, A. C. (2001). A contabilidade gerencial e os métodos multicriteriais. Revista de Contabilidade e Finanças da USP, v. 14, n. 25.

Data de Submissão:16/09/2010

Data de Aceite: 06/06/2012 